\title{
La logística y la integración a las cadenas globales de valor
}

Elsa Marinucci ${ }^{*}$

\section{Resumen}

En los años recientes, las naciones han reconocido, quizás con mayor fuerza que antes, la importancia del comercio mundial para el logro del crecimiento económico sustentable. Por ello, este artículo está referido a la trascendencia de la logística como un sector de apoyo al desarrollo exportador de los países y por ende, al crecimiento económico sustentable. En contraste con la visión tradicional de los negocios, donde el foco estaba puesto en la producción, en el mundo actual las empresas que operan globalmente ven a la logística como una poderosa herramienta generadora de ventajas estratégicas y competitivas que posibilita la integración a las cadenas de valor globales.

Por tanto en este trabajo se realizará un recorrido por los principales componentes que miden el desempeño logístico de un país, para posteriormente mostrar cómo se encuentran dichos componentes en América Latina y en Argentina en particular. Estos datos sobre el desempeño permitirán visualizar la brecha existente con aquellos países mejor posicionados y así determinar cuáles son las acciones de políticas para mejorar los índices actuales y disminuir dicha brecha.

Palabras claves: Logística - cadenas de suministros - desarrollo exportador - competitividad previsibilidad

\section{Logistics and integration into global value chains}

\begin{abstract}
In recent years countries have realized, perhaps more than ever, the importance of trade to achieving sustainable economic growth. This article is based on the relevance of logistics to achieve sustained economic development based on international competitiveness. In contrast to the traditional view of business where the focus was on production, currently global companies see logistics as a powerful tool to generate strategic and competitive advantages that enables the connection to those global value chains. Logistics connects firms to international markets through reliable supply chain networks. The aim of this article is, therefore, to review the main logistics performance components in Latin America and especially in Argentina to show the relationship between those components and their competitiveness. These performance data will allow to visualize the gap with the best positioned countries and identify policy actions for improving the current rates and reduce the gap.
\end{abstract}

Key words: Logistics - supply chain - export development - competitiveness - predictable

Trabajo enviado: 30/10/2016 Trabajo aceptado: 02/12/2016

\section{Introducción}

En el mundo actual, la logística ha adquirido especial relevancia, dado que es un componente fundamental para el desarrollo exportador y la integración de las empresas en el comercio internacional. En las formas tradicionales de comercio, un producto era elaborado casi totalmente en un único país y luego se exportaba a otros. A partir de los años '70, parte de la cadena de valor comienza a ser realizada fuera de las fronteras. Pero ya en los años '80, la producción comienza a fragmentarse en diferentes etapas dispersas en una multiplicidad de mercados, para luego ser unidas a través de complejos sistemas logísticos que permitirán alcanzar los mercados globales.

\footnotetext{
* Doctora en Relaciones Internacionales, Universidad Nacional de Rosario (UNR, Argentina); Docente e Investigadora de la Universidad Abierta Interamericana. Contacto: elsa@trans-modal.com.ar
} 
Hoy es ampliamente reconocido que el comercio internacional es uno de los motores del desarrollo económico. Para dicho desarrollo, es necesario alcanzar un elevado impulso exportador que posibilite la integración a las cadenas globales de valor. La logística es el eslabón que otorga la previsibilidad y confiabilidad demandada para el recorrido de esas exportaciones.

La expansión hacia otros mercados permite explotar economías de escala, mejorar la programación de la producción, diversificar riesgos y lograr un mejor aprovechamiento de las instalaciones, entre otros beneficios. Asimismo las exportaciones promueven la competencia, ya que, quien logra colocar sus productos en el resto del mundo, ha podido enfrentar y superar a los competidores de los demás mercados, por lo que la exportación alienta la innovación y la productividad permitiendo equilibrarse contra la entrada de competidores en el comercio interno.

La logística es globalmente considerada uno de los pilares claves del desarrollo exportador y el comercio internacional, por lo que contribuye significativamente al crecimiento económico y la competitividad. Está fuertemente vinculada con la confiabilidad de las cadenas de suministros y la previsibilidad de los servicios de entrega, tanto para productores como para comercializadores, exportadores e importadores de bienes. Si consideramos que las cadenas de suministros se están tornando cada vez más complejas, la logística se convierte en la herramienta fundamental para el éxito de la integración de los bienes a esas cadenas de valor mundiales.

La dinámica de los cambios actuales plantea a las empresas y gobiernos la necesidad de transformarse para acompañar esos retos. La integración a las cadenas de valor es un aspecto muy importante para alcanzar el desarrollo exportador de un Estado y/o región y para ello, es necesario traer a consideración que la globalización de los mercados y el acelerado avance tecnológico han modificado radicalmente el contexto del comercio internacional en que debe insertarse ese Estado o región. El proceso de fragmentación de la producción antes mencionado, donde un producto se ensambla en un país con componentes de varios, ha generado un aumento de la demanda de mayor calidad, eficiencia, certeza y servicios de valor agregado incluido en los productos. Por ello, las cadenas globales de valor requieren de una logística muy precisa, confiable y que posibilite la optimización de costos. En este contexto, las organizaciones que se expanden más enérgicamente al mundo en la continua búsqueda de más y nuevos clientes, se transforman en grandes demandantes de logística como sector de apoyo a esta expansión. Esta demanda comienza a ejercer una fuerte presión sobre los servicios de logística que una nación es capaz de brindar y sobre los proveedores logísticos privados insertos en ella, quienes se verán exigidos a ajustarse a los plazos, tiempos, costos y normas de calidad que esa demanda requiere.

$\mathrm{Si}$ consideramos que las medidas de facilitación del comercio y las inversiones posibilitan a las organizaciones producir en aquellos espacios que ofrecen mejores condiciones para la competitividad, aquellas naciones que no logren adaptarse a esa demanda, serán sustituidas rápidamente por otras dispuestas a acoger en su territorio a esos eslabones en las cadenas de valor más eficientemente. La puja ya no es solo por espacios de mercado entre organizaciones sino por la atracción de inversiones entre Estados. La conectividad global genera que muchas naciones busquen transformarse en una base para la provisión de servicios logísticos claves o centros logísticos que abastecen de esta clase de servicios a empresas de toda una región e incluso del mundo entero. ${ }^{1}$

Asimismo, aquellos proveedores privados de servicios logísticos que no logren ajustarse al desempeño demandado por las organizaciones, dejarán un espacio vacío que será ocupado por proveedores que, a través de las redes globales de comunicación, ofrecerán sus servicios desde cualquier lugar del mundo. Por esto, el margen para permanecer aislados de la competencia global es cada vez más estrecho y menos factible.

\footnotetext{
${ }^{1}$ El caso de Países Bajos, Singapur, Emiratos Árabes o Panamá convirtiéndose en verdaderos centros logísticos regionales y mundiales, son ejemplo de ello.
} 


\section{Conceptualizaciones y componentes de la logística}

La logística se ha convertido en una disciplina clave para competir en el nuevo entorno global debido a que se ocupa de administrar el flujo de materiales a través de una organización, desde el abastecimiento de la materia prima en el país proveedor, hasta la entrega del producto terminado en el local del comprador en algún lugar del mundo, con el fin último de generar la máxima satisfacción del consumidor.

Muchas son las definiciones de logística desde su nacimiento como disciplina. Desde aquellas surgidas en el área militar ${ }^{2}$ como disciplina especializada en el control de flujos movimiento, transporte y localización de tropas- para la guerra, hasta las actuales definiciones del mundo empresarial que la transformaron en una poderosa herramienta de gestión. En este ámbito, la logística tiene una estrecha vinculación con la rentabilidad. El Council of Supply Chain Management Professionals ${ }^{3}$ la define como "el proceso de planeación, implementación y control de los procedimientos para la eficiencia y efectividad del transporte y almacenaje de mercaderías, incluyendo servicios e información relacionada, desde el punto de origen al punto de destino de consumo, con el propósito de satisfacer los requerimientos del cliente". Esta definición incluye las entradas y salidas de una organización y todos los movimientos internos y externos a ella. ${ }^{4}$

En función de esto, entenderemos aquí por logística a un concepto amplio y como una especialidad que genera valor al proceso productivo. Por esto, frecuentemente se afirma que la logística es una parte del arte del comercio y se la incluye dentro del desarrollo de todo plan y resolución de problema comercial, tanto estratégico como táctico.

Dentro de la logística cobran importancia la gestión de compras, de stocks, de almacenes, la producción, embalaje, transporte, distribución, entrega y los seguros que cubren todo el proceso necesario para el traslado de la mercadería desde el mercado de producción al de consumo. A la logística internacional debemos agregarle la gestión aduanera y una selección más compleja del embalaje y de los modos de transporte dadas las mayores distancias entre productor y consumidor. Decimos que la selección del modo es compleja porque esta elección puede condicionar el resto de operaciones. Por ejemplo, el modo de transporte utilizado -aéreo, acuático o terrestre- condicionará los plazos de entrega y/o el estado y condición de la mercadería al momento de su llegada. Asimismo, la frecuencia en las entregas y las demoras en los tiempos de tránsito pueden agravar o entorpecer los stocks, afectando la competitividad de las organizaciones dado el costo adicional que esto generará. Por el lado del embalaje, no serán las mismas las consideraciones sobre la protección necesaria para la mercadería en un traslado dentro del mercado doméstico, que entre varios países o continentes, donde pueden intervenir más de un medio de transporte y con varios transbordos.

Frecuentemente vemos limitar las decisiones de logística al análisis exclusivo del transporte, lo cual es dar una visión parcial a dicho análisis, debido a que se dejan de lado

\footnotetext{
${ }^{2}$ La Escuela de Guerra Naval de la Marina Española define a la logística como "la parte del arte de la guerra que tiene por objeto proporcionar a las fuerzas armadas los medios de personal, material y servicios necesarios para satisfacer con cantidad, calidad, momento y lugar adecuados las exigencias de la guerra".

3 El Council of Supply Chain Management Professionals se originó en 1963 como una asociación sin fines de lucro de profesionales de Cadenas de Suministros, dedicada a la promoción y difusión de la investigación y el conocimiento sobre la gestión de dichas cadenas. Su objetivo es apoyar a sus miembros en la gestión de cadenas de suministros. Cuenta con más de 9.000 miembros, y es la primera Asociación Mundial de Profesionales del sector. Tiene su base central en Estados Unidos y cuenta con delegaciones en 71 países.

${ }^{4}$ Definición extraída del COUNCIL OF SUPPLY CHAIN MANAGEMENT PROFESSIONALS (2013) Supply Chain Management Terms and Glossary. Updated August 2013. Disponible en https://cscmp.org/sites/ default/files/user_uploads/ resources/downloads/glossary2013.pdf?utm_source=cscmpsite\& utm_medium=clicklinks\&utm_ content=glossary\&utm_campaign= GlossaryPDF. Consulta: 2 de septiembre de 2016.
} 
muchos componentes que son relevantes al momento de la planeación e implementación del flujo de productos. No solo importa que el producto llegue a destino, sino cómo llega, cuándo llega y a qué costo efectivo total lo hace. Si bien el transporte es un elemento influyente que condiciona gran parte del resto de los componentes, existen otros también relevantes que contribuyen significativamente a que el desarrollo logístico de una región o un país sea posible, tal es el caso de la infraestructura física adecuada, los modernos sistemas de comunicaciones, la gestión eficiente y transparente de los procedimientos en aduanas o los recursos humanos especializados.

En este trabajo se realizará una descripción de los principales condicionantes del desempeño logístico de América Latina y de Argentina y de cada uno de sus componentes, para así visualizar las variables prioritarias de focalización de políticas para el establecimiento de una agenda en logística que facilite el comercio y posibilite una inserción más sustentable de las empresas regionales en las cadenas de valor mundiales.

\section{El desempeño logístico global: un marco de comparación}

Para analizar el desempeño logístico de América Latina, es necesario remitirnos al desempeño de aquellas naciones que fueron pioneras en el desarrollo de la logística empresarial y cuyo resultado, después de su aplicación, derivó en organizaciones exitosamente internacionalizadas. ${ }^{5}$ En la comparación global, América Latina experimenta importantes cuellos de botella que atentan con la previsibilidad de las cadenas de suministros y por ende contra la integración a los eslabones de valor mundiales. Varios autores, entre ellos Mesquita Moreira, Blyde, Volpe Martincus, Molina o Muir, señalan que los costos logísticos de esta región oscilan entre el $18 \%$ y $35 \%$ del valor final de los productos, muy por arriba del $8 \%$ de los países de la Organización para la Cooperación y el Desarrollo Económico (OCDE) (Mesquita Moreira, et al., 2013). Las organizaciones que más deben soportar los inconvenientes de esa brecha son las micro, pequeñas y medianas empresas (MIPYMES), donde este porcentaje puede incluso superar el 40\% (Muir, 2016).

Una orientación sobre las anteriores dificultades la podemos observar en el Índice de Desempeño Logístico (LPI, por sus siglas en inglés), que elabora el Banco Mundial. Dicho índice es confeccionado desde el año 2007, planteando el debate entre el rol de la logística para el crecimiento y las políticas llevadas a cabo en áreas como infraestructura, provisión de servicios y facilitación del comercio a través de las fronteras. ${ }^{6}$ El índice toma una muestra de 160 países, evalúa según una escala de 1 a 5 puntos donde 5 equivale al mejor desempeño y es realizado cada dos años. Realiza los análisis en base a seis dimensiones de comercio incluyendo el funcionamiento de la aduana, calidad de la infraestructura y puntualidad en los embarques-, reconocidas como importantes para el desarrollo. ${ }^{7}$ Las dimensiones analizadas son:

\footnotetext{
${ }^{5}$ Una empresa u organización -ya sea productora de bienes o servicios-, está internacionalizada cuando su presencia y/o la de los bienes o servicios que produce es permanente y no ocasional en mercados externos. A su vez, posee una clara intención de asignar un porcentaje significativo de su producción hacia el exterior. Esta presencia puede darse no solo a través de la exportación sino también a través de la inversión directa o asociativa.

${ }^{6}$ El término facilitación del comercio es utilizado en los acuerdos comerciales como el "Acuerdo sobre Facilitación del Comercio" de la OMC y se refiere a las mejoras en los procedimientos aduaneros y otros procedimientos a realizar en frontera para facilitar y agilizar la importación y exportación para las empresas.

${ }^{7}$ El Índice de Desempeño Logístico permite verificar el desempeño de cada país año tras año y evaluar las acciones a tomar por parte de gobiernos y actores privados, ya que analiza aspectos vinculados a políticas públicas como infraestructura y aspectos de desempeño de empresas de servicios logísticos como posibilidad de seguimiento de envíos. Está basado en encuestas a transitarios -freight forwarders- y transportistas globales.
} 
1. Aduanas: la eficiencia en las aduanas y la gestión del despacho en las fronteras.

2. Infraestructura: la calidad de la infraestructura para el transporte y el comercio.

3. Competencia y la calidad de los servicios logísticos (servicios de agenciamiento, transportes y gestiones de aduana)

4. Precios de los envíos: la facilidad para organizar los envíos a precios competitivos

5. Seguimiento y rastreo de los envíos: la capacidad de seguimiento y localización de los envíos

6. Oportunidad de los envíos: la frecuencia con la que los envíos llegan a los destinatarios dentro de los plazos de entrega previstos o esperados

El Índice de 2016 (Banco Mundial, 2016), que podemos observar en el cuadro I, sitúa a Alemania como el país con mejor desempeño, con 4.23 puntos y número uno en la lista, mientras que en el otro extremo sitúa a Siria con el peor desempeño, en el puesto ciento sesenta con 1.60 puntos. Si extendemos el análisis a los cinco primeros países con mejor desempeño, después de Alemania encontramos a Luxemburgo, ubicado en segundo lugar con 4.22 puntos; luego encontramos a Suecia, con 4.20 puntos, Países Bajos en cuarto lugar con 4.19 puntos y Singapur en quinto lugar con 4.14 puntos. Por el lado de aquellos países con más bajo desempeño tenemos, además de Siria y ubicados por arriba de este, a Haití con 1.72 puntos, Somalia, quien mejoró dos lugares con respecto a 2014 y califica con 1.75 puntos, luego se presenta Mauritania con 1.87 puntos y en el puesto número ciento cincuenta y seis se ubica Guinea Ecuatorial con 1.88 puntos.

De los primeros treinta países con mejor desempeño, ninguno de ellos se encuentra en América Latina. La mayoría de esos treinta corresponde a miembros de la Unión Europea y de la OCDE -catorce y veintidós, respectivamente-. Para el caso de América Latina, recién encontramos a Panamá en el puesto cuarenta, Chile en el cuarenta y seis, México en el cincuenta y cuatro, Brasil en el cincuenta y cinco, Uruguay en el sesenta y cinco o Argentina en el sesenta y seis. 


\section{Cuadro I}

\section{Ranking de desempeño logístico 2016}

\begin{tabular}{|c|c|c|c|c|c|c|c|c|c|c|c|c|c|c|c|c|c|c|c|}
\hline \multirow[b]{2}{*}{ Economy } & \multicolumn{3}{|c|}{ LPI rank } & \multicolumn{3}{|c|}{ LPI score } & \multirow{2}{*}{$\begin{array}{c}\begin{array}{c}\% \text { of } \\
\text { highest } \\
\text { performer }\end{array} \\
\end{array}$} & \multicolumn{2}{|c|}{ Customs } & \multicolumn{2}{|c|}{ Infrastructure } & \multicolumn{2}{|c|}{$\begin{array}{l}\text { International } \\
\text { shipments }\end{array}$} & \multicolumn{2}{|c|}{$\begin{array}{l}\text { Logistics } \\
\text { quality and } \\
\text { competence }\end{array}$} & \multicolumn{2}{|c|}{$\begin{array}{l}\text { Tracking and } \\
\text { tracing }\end{array}$} & \multicolumn{2}{|c|}{ Timeliness } \\
\hline & Rank & $\begin{array}{l}\text { Lower } \\
\text { bound }\end{array}$ & $\begin{array}{l}\text { Upper } \\
\text { bound }\end{array}$ & Score & $\begin{array}{l}\text { Lower } \\
\text { bound }\end{array}$ & $\begin{array}{l}\text { Upper } \\
\text { bound }\end{array}$ & & Rank & Score & Rank & Score & Rank & Score & Rank & Score & Pank & Score & Rank & Score \\
\hline Germany & 1 & 1 & 4 & 4.23 & 4.18 & 4.27 & 100.0 & 2 & 4.12 & 1 & 4.44 & 8 & 3.86 & 1 & 4.28 & 3 & 4.27 & 2 & 4.45 \\
\hline Luxembourg & 2 & 1 & 12 & 4.22 & 3.97 & 4.47 & 99.8 & 9 & 3.90 & 4 & 4.24 & 1 & 4.24 & 10 & 4.01 & 8 & 4.12 & 1 & 4.80 \\
\hline Sweden & 3 & 1 & 7 & 4.20 & 4.09 & 4.32 & 99.3 & 8 & 3.92 & 3 & 4.27 & 4 & 4.00 & 2 & 4.25 & 1 & 4.38 & 3 & 4.45 \\
\hline Netherlands & 4 & 1 & 6 & 4.19 & 4.11 & 4.27 & 98.8 & 3 & 4.12 & 2 & 4.29 & 6 & 3.94 & 3 & 4.22 & 6 & 4.17 & 5 & 4.41 \\
\hline Singapore & 5 & 2 & 9 & 4.14 & 4.06 & 4.22 & 97.4 & 1 & 4.18 & 6 & 4.20 & 5 & 3.96 & 5 & 4.09 & 10 & 4.05 & 6 & 4.40 \\
\hline Belgium & 6 & 5 & 9 & 4.11 & 4.04 & 4.18 & 96.4 & 13 & 3.83 & 14 & 4.05 & 3 & 4.05 & 6 & 4.07 & 4 & 4.22 & 4 & 4.43 \\
\hline Austria & 7 & 3 & 11 & 4.10 & 3.98 & 4.21 & 96.0 & 15 & 3.79 & 12 & 4.08 & 9 & 3.85 & 4 & 4.18 & 2 & 4.36 & 7 & 4.37 \\
\hline United Kingdom & 8 & 6 & 9 & 4.07 & 4.03 & 4.11 & 95.2 & 5 & 3.98 & 5 & 4.21 & 11 & 377 & 7 & 4.05 & 7 & 4.13 & 8 & 4.33 \\
\hline $\begin{array}{l}\text { Hong Kong } \\
\text { SAR, China }\end{array}$ & 9 & 6 & 9 & 4.07 & 4.00 & 4.14 & 95.1 & 7 & 3.94 & 10 & 4.10 & 2 & 4.05 & 11 & 4.00 & 14 & 4.03 & 9 & 4.29 \\
\hline United States & 10 & 10 & 12 & 3.99 & 3.94 & 4.04 & 92.8 & 16 & 3.75 & 8 & 4.15 & 19 & 3.65 & 8 & 4.01 & 5 & 4.20 & 11 & 4.25 \\
\hline Switzerland & 11 & 10 & 15 & 3.99 & 3.92 & 4.06 & 92.6 & 10 & 3.88 & 7 & 4.19 & 14 & 3.69 & 14 & 3.95 & 12 & 4.04 & 14 & 4.24 \\
\hline Japan & 12 & 10 & 15 & 397 & 3.92 & 4.02 & 92.1 & 11 & 3.85 & 11 & 4.10 & 13 & 3.69 & 12 & 3.99 & 13 & 4.03 & 15 & 4.21 \\
\hline $\begin{array}{l}\text { United Arab } \\
\text { Emirates }\end{array}$ & 13 & 10 & 16 & 3.94 & 3.88 & 4.00 & 91.2 & 12 & 3.84 & 13 & 4.07 & 7 & 3.89 & 18 & 3.82 & 18 & 391 & 18 & 4.13 \\
\hline Canada & 14 & 10 & 16 & 393 & 3.83 & 4.03 & 90.8 & 6 & 3.95 & 9 & 4.14 & 29 & 3.56 & 15 & 3.90 & 9 & 4.10 & 25 & 4.01 \\
\hline Finland & 15 & 9 & 20 & 3.92 & 3.77 & 4.07 & 90.5 & 4 & 4.01 & 16 & 4.01 & 30 & 3.51 & 16 & 3.88 & 11 & 4.04 & 16 & 4.14 \\
\hline France & 16 & 13 & 16 & 3.90 & 3.84 & 3.96 & 89.9 & 17 & 3.71 & 15 & 4.01 & 20 & 3.64 & 19 & 3.82 & 15 & 4.02 & 13 & 4.25 \\
\hline Denmark & 17 & 6 & 30 & 3.82 & 3.51 & 4.12 & 87.3 & 14 & 3.82 & 24 & 3.75 & 15 & 3.66 & 9 & 4.01 & 25 & 3.74 & 30 & 3.92 \\
\hline Ireland & 18 & 11 & 30 & 3.79 & 3.60 & 3.99 & 86.6 & 25 & 3.47 & 22 & 3.77 & 10 & 3.83 & 20 & 3.79 & 16 & 3.98 & 29 & 3.94 \\
\hline Australia & 19 & 10 & 30 & 3.79 & 3.58 & 4.00 & 86.6 & 22 & 3.54 & 18 & 3.82 & 21 & 3.63 & 17 & 3.87 & 19 & 3.87 & 21 & 4.04 \\
\hline South Africa & 20 & 17 & 24 & 378 & 3.70 & 3.85 & 86.0 & 18 & 3.60 & 21 & 3.78 & 23 & 3.62 & 22 & 3.75 & 17 & 3.92 & 24 & 4.02 \\
\hline ithy & 21 & 18 & 24 & 3.76 & 3.70 & 3.81 & 85.4 & 27 & 3.45 & 19 & 3.79 & 17 & 3.65 & 21 & 3.77 & 20 & 3.86 & 22 & 4.03 \\
\hline Norway & 22 & 15 & 30 & 3.73 & 3.54 & 3.92 & 84.7 & 20 & 3.57 & 17 & 3.95 & 25 & 3.62 & 24 & 370 & 22 & 3.82 & 39 & 3.77 \\
\hline Spain & 23 & 17 & 29 & 3.73 & 3.62 & 3.84 & 84.5 & 24 & 3.48 & 25 & 3.72 & 22 & 3.63 & 23 & 3.73 & 23 & 3.82 & 26 & 4.00 \\
\hline Korea, Rep. & 24 & 20 & 28 & 3.72 & 3.64 & 3.79 & 84.2 & 26 & 3.45 & 20 & 3.79 & 27 & 3.58 & 25 & 3.69 & 24 & 3.78 & 23 & 4.03 \\
\hline Taiwan, China & 25 & 15 & 30 & 3.70 & 3.47 & 3.92 & 83.6 & 34 & 3.23 & 26 & 3.57 & 28 & 3.57 & 13 & 3.95 & 31 & 3.59 & 12 & 4.25 \\
\hline Crech Aepublic & 26 & 17 & 30 & 3.67 & 3.52 & 3.83 & 829 & 19 & 3.58 & 35 & 3.36 & 18 & 3.65 & 26 & 3.65 & 21 & 3.84 & 28 & 394 \\
\hline China & 27 & 25 & 29 & 3.66 & 3.61 & 3.71 & 82.5 & 31 & 3.32 & 23 & 3.75 & 12 & 3.70 & 27 & 362 & 28 & 3.68 & 31 & 3.90 \\
\hline Israel & 28 & 17 & 30 & 3.66 & 3.47 & 3.85 & 82.5 & 23 & 3.50 & 30 & 3.49 & 37 & 3.38 & 28 & 3.60 & 26 & 3.72 & 10 & 4.27 \\
\hline Lithuania & 29 & 18 & 30 & 3.63 & 3.45 & 3.82 & 81.6 & 28 & 3.42 & 27 & 3.57 & 31 & 3.49 & 30 & 3.49 & 27 & 3.68 & 17 & 4.14 \\
\hline Qatar & 30 & 17 & 38 & 3.60 & 3.36 & 3.84 & 80.6 & 21 & 3.55 & 28 & 3.57 & 26 & 3.58 & 29 & 3.54 & 35 & 3.50 & 35 & 3.83 \\
\hline Hungary & 31 & 31 & 44 & 3.43 & 3.30 & 3.56 & 75.3 & 49 & 3.02 & 32 & 3.48 & 34 & 3.44 & 34 & 3.35 & 41 & 3.40 & 33 & 3.88 \\
\hline Malaysia & 32 & 31 & 41 & 3.43 & 3.34 & 3.52 & 75.2 & 40 & 3.17 & 33 & 3.45 & 32 & 3.48 & 35 & 334 & 36 & 3.46 & 47 & 3.65 \\
\hline Poland & 33 & 31 & 44 & 3.43 & 3.30 & 3.56 & 75.2 & 33 & 3.27 & 45 & 3.17 & 33 & 3.44 & 31 & 3.39 & 37 & 3.46 & 37 & 3.80 \\
\hline Turkey & 34 & 31 & 44 & 3.42 & 3.28 & 3.56 & 75.1 & 36 & 3.18 & 31 & 3.49 & 35 & 3.41 & 36 & 3.31 & 43 & 3.39 & 40 & 3.75 \\
\hline India & 35 & 31 & 38 & 3.42 & 3.36 & 3.48 & 75.0 & 38 & 3.17 & 36 & 3.34 & 39 & 3.36 & 32 & 3.39 & 33 & 3.52 & 42 & 3.74 \\
\hline Portugal & 36 & 31 & 44 & 3.41 & 3.27 & 3.55 & 74.7 & 30 & 3.37 & 49 & 3.09 & 47 & 3.24 & 47 & 3.15 & 29 & 365 & 27 & 3.95 \\
\hline New Zealand & 37 & 25 & 56 & 3.39 & 3.07 & 3.71 & 74.0 & 37 & 3.18 & 29 & 3.55 & 80 & $2 \pi$ & 41 & 3.22 & 32 & 3.58 & 19 & 4.12 \\
\hline Estonia & 38 & 31 & 53 & 3.36 & 3.13 & 3.60 & 73.3 & 29 & 3.41 & 44 & 3.18 & 56 & 3.07 & 46 & 3.18 & 48 & 3.25 & 20 & 4.08 \\
\hline Iceland & 39 & 30 & 55 & 3.35 & 3.07 & 3.62 & 72.7 & 43 & 3.13 & 51 & 3.02 & 42 & 3.32 & 39 & 3.26 & 40 & 3.42 & 32 & 3.88 \\
\hline Panama & 40 & 30 & 56 & 334 & 3.07 & 361 & 725 & 42 & 3.13 & 38 & 3.28 & 16 & 3.65 & 45 & 3.18 & 63 & 295 & 41 & 3.74 \\
\hline Slovak Republic & 41 & 31 & 53 & 3.34 & 3.12 & 3.56 & 72.4 & 32 & 3.28 & 39 & 3.24 & 36 & 3.41 & 51 & 3.12 & 55 & 3.12 & 36 & 3.81 \\
\hline Kenya & 42 & 31 & 48 & 3.33 & 3.21 & 3.45 & 72.3 & 39 & 3.17 & 42 & 3.21 & 46 & 3.24 & 40 & 3.24 & 38 & 3.42 & 46 & 3.70 \\
\hline
\end{tabular}




\begin{tabular}{|c|c|c|c|c|c|c|c|c|c|c|c|c|c|c|c|c|c|c|c|}
\hline \multirow[b]{2}{*}{ Economy } & \multicolumn{3}{|c|}{ LPI rank } & \multicolumn{3}{|c|}{ LPI score } & \multirow{2}{*}{$\begin{array}{c}\begin{array}{c}\% \text { of } \\
\text { highest } \\
\text { performer }\end{array}\end{array}$} & \multicolumn{2}{|c|}{ Customs } & \multicolumn{2}{|c|}{ Infrastructure } & \multicolumn{2}{|c|}{$\begin{array}{l}\text { International } \\
\text { shipments }\end{array}$} & \multicolumn{2}{|c|}{$\begin{array}{l}\text { Logistics } \\
\text { quality and } \\
\text { competence }\end{array}$} & \multicolumn{2}{|c|}{$\begin{array}{l}\text { Tracking and } \\
\text { tracing }\end{array}$} & \multicolumn{2}{|c|}{ Timeliness } \\
\hline & Rank & $\begin{array}{l}\text { Lower } \\
\text { bound }\end{array}$ & $\begin{array}{l}\text { Upper } \\
\text { bound }\end{array}$ & Score & $\begin{array}{l}\text { Lower } \\
\text { bound }\end{array}$ & $\begin{array}{l}\text { Upper } \\
\text { bound }\end{array}$ & & Rank & Score & Rank & Score & Rank & Score & Rank & Score & Rank & Score & Rank & Score \\
\hline Latvia & 43 & 31 & 53 & 3.33 & 3.12 & 3.53 & 72.1 & 45 & 3.11 & 41 & 3.24 & 44 & 3.28 & 37 & 3.29 & 39 & 3.42 & 49 & 3.62 \\
\hline Bahrain & 44 & 31 & 53 & 3.31 & 3.11 & 3.51 & 71.7 & 41 & 3.14 & 48 & 3.10 & 41 & 3.33 & 33 & 3.38 & 44 & 3.32 & 51 & 3.58 \\
\hline Thalland & 45 & 43 & 50 & 3.26 & 3.18 & 3.33 & 69.9 & 46 & 3.11 & 46 & 3.12 & 38 & 3.37 & 49 & 3.14 & 50 & 3.20 & 52 & 3.56 \\
\hline Chille & 46 & 31 & 58 & 3.25 & 3.00 & 3.50 & 69.7 & 35 & 3.19 & 63 & $2 \pi$ & 43 & 3.30 & 56 & 297 & 34 & 3.50 & 44 & 3.71 \\
\hline Greece & 47 & 38 & 54 & 3.24 & 3.10 & 3.38 & 69.4 & 55 & 285 & 37 & 3.32 & 64 & 2.97 & 60 & 2.91 & 30 & 3.59 & 34 & 3.85 \\
\hline Oman & 48 & 31 & 58 & 323 & 3.00 & 3.47 & 69.3 & 61 & 2.76 & 34 & 3.44 & 40 & 3.35 & 38 & 3.26 & 57 & 3.09 & 57 & 3.50 \\
\hline Egypt, Arab Rep. & 49 & 44 & 56 & 3.18 & 3.05 & 3.32 & 677 & 65 & 275 & 50 & 3.07 & 45 & 3.27 & 43 & 3.20 & 54 & 3.15 & 48 & 3.63 \\
\hline Slovenia & 50 & 35 & 67 & 3.18 & 2.95 & 3.42 & 67.7 & 53 & 2.88 & 43 & 3.19 & 53 & 3.10 & 44 & 3.20 & 46 & 327 & 60 & 3.47 \\
\hline Croatia & 51 & 37 & 67 & 3.16 & 2.93 & 3.39 & 67.0 & 47 & 3.07 & 53 & 2.99 & 51 & 3.12 & 42 & 3.21 & 52 & 3.16 & 67 & 3.39 \\
\hline Saudi Arabla & 52 & 45 & 58 & 3.16 & 3.03 & 3.28 & 66.8 & 68 & 2.69 & 40 & 3.24 & 48 & 3.23 & 54 & 3.00 & 49 & 3.25 & 53 & 3.53 \\
\hline Kuwait & 53 & 40 & 66 & 3.15 & 2.96 & 3.35 & 66.7 & 56 & 2.83 & 56 & 2.92 & 24 & 3.62 & 70 & 2.79 & 53 & 3.16 & 55 & 3.51 \\
\hline Merico & 54 & 45 & 66 & 3.11 & 2.96 & 327 & 65.5 & 54 & 288 & 57 & 2.89 & 61 & 3.00 & 48 & 3.14 & 42 & 3.40 & 68 & 3.38 \\
\hline Brazil & 55 & 49 & 62 & 3.09 & 299 & 3.19 & 64.7 & 62 & 276 & 47 & 3.11 & 72 & 2.90 & 50 & 3.12 & 45 & 328 & 66 & 3.39 \\
\hline Mata & 56 & 45 & 71 & 3.07 & 284 & 3.30 & 64.1 & 59 & 2.78 & 55 & 2.94 & 55 & 3.09 & 65 & 2.85 & 56 & 3.12 & 50 & 3.61 \\
\hline Botswana & 57 & 45 & 71 & 3.05 & 2.82 & 3.27 & 63.4 & 48 & 3.05 & 54 & 2.96 & 70 & 2.91 & 75 & 2.74 & 70 & 2.89 & 43 & 3.72 \\
\hline Uganda & 58 & 53 & 67 & 3.04 & 2.93 & 3.15 & 63.3 & 51 & 297 & 67 & 2.74 & 74 & 2.88 & 57 & 293 & 59 & 3.01 & 45 & 3.70 \\
\hline Cyprus & 59 & 49 & 73 & 3.00 & 2.78 & 3.22 & 62.0 & 44 & 3.11 & 52 & 3.00 & 78 & 2.80 & 76 & 272 & 98 & 2.54 & 38 & 3.79 \\
\hline Romania & 60 & 51 & 72 & 299 & 2.81 & 3.18 & 61.8 & 50 & 3.00 & 58 & 2.88 & 57 & 3.06 & 67 & 282 & 64 & 2.95 & 81 & 3.22 \\
\hline Tanzania & 61 & 56 & 68 & 2.99 & 2.89 & 3.09 & 61.7 & 60 & 2.78 & 60 & 281 & 63 & 2.98 & 58 & 2.92 & 60 & 2.98 & 64 & 3.44 \\
\hline Rwanda & 62 & 51 & 72 & 2.99 & 2.80 & 3.17 & 61.6 & 52 & 2.93 & 76 & 262 & 59 & 3.05 & 63 & 2.87 & 58 & 3.04 & 69 & 3.35 \\
\hline Indonesia & 63 & 51 & 72 & 2.98 & 2.80 & 3.17 & 61.5 & 69 & 2.69 & 73 & 265 & 71 & 2.90 & 55 & 3.00 & 51 & 3.19 & 62 & 3.46 \\
\hline Vetnam & 64 & 49 & 76 & 298 & 276 & 320 & 61.3 & 64 & 275 & 70 & 270 & 50 & 3.12 & 62 & 288 & 75 & 284 & 56 & 350 \\
\hline Uruguar & 65 & 51 & 73 & 297 & 279 & 3.16 & 61.2 & 58 & 278 & 61 & 279 & 69 & 2.91 & 53 & 3.01 & 74 & 2.84 & 59 & 3.47 \\
\hline Airgentina & 66 & 55 & 71 & 296 & 281 & 3.11 & 60.8 & 76 & 2.63 & 59 & 286 & 81 & 276 & 66 & 283 & 47 & 3.26 & 61 & 3.47 \\
\hline Jordan & 67 & 51 & 79 & 2.96 & 2.74 & 3.17 & 60.7 & 83 & 2.55 & 62 & 277 & 49 & 3.17 & 61 & 2.89 & 62 & 296 & 71 & 3.34 \\
\hline Pakistan & 68 & 59 & 71 & 2.92 & 2.81 & 3.04 & 59.6 & 71 & 2.66 & 69 & 270 & 66 & 2.93 & 68 & 2.82 & 67 & 2.91 & 58 & 3.48 \\
\hline Peru & 69 & 57 & 81 & 2.89 & 2.72 & 3.06 & 58.7 & 63 & 2.76 & 75 & 262 & 68 & 2.91 & 64 & 2.87 & 65 & 294 & 80 & 3.23 \\
\hline $\begin{array}{l}\text { Brunel } \\
\text { Darussalam }\end{array}$ & 70 & 51 & 98 & 287 & 2.57 & 3.17 & 58.0 & 57 & 278 & 66 & 2.75 & 62 & 3.00 & 93 & 2.57 & 68 & 2.91 & 84 & 3.19 \\
\hline Philippines & 71 & 60 & 82 & 2.86 & 2.72 & 3.00 & 57.5 & 78 & 2.61 & 82 & 2.55 & 60 & 3.01 & 77 & 2.70 & 73 & 2.86 & 70 & 3.35 \\
\hline Bulgaria & 72 & 57 & 100 & 2.81 & 2.56 & 3.05 & 56.0 & 97 & 2.40 & 101 & 2.35 & 67 & 2.93 & 52 & 3.06 & 80 & 2.72 & 72 & 3.31 \\
\hline Canbodia & 73 & 59 & 99 & 280 & 2.57 & 3.04 & 55.8 & $\pi 7$ & 2.62 & 99 & 2.36 & 52 & 3.11 & 89 & 2.60 & 81 & 270 & 73 & 3.30 \\
\hline Ecuador & 74 & 60 & 99 & 278 & 2.56 & 2.99 & 55.1 & 74 & 264 & 88 & 247 & 65 & 2.95 & 84 & 2.66 & 86 & 265 & $n$ & 323 \\
\hline Algeria & 75 & 59 & 107 & $2 \pi 7$ & 2.51 & 303 & 54.9 & 108 & 237 & 80 & 2.58 & 77 & 2.80 & 59 & 2.91 & 72 & 286 & 91 & 3.08 \\
\hline Sertia & 76 & 66 & 101 & 276 & 2.56 & 2.97 & 54.6 & 87 & 2.50 & 85 & 2.49 & 90 & 2.63 & 69 & 279 & 66 & 292 & 79 & 3.23 \\
\hline Karzakhstan & 77 & 68 & 101 & 275 & 255 & 295 & 54.3 & 86 & 252 & 65 & 276 & 82 & 275 & 92 & 2.57 & 71 & 286 & 92 & 3.06 \\
\hline Bahamas, The & 78 & 69 & 98 & 275 & 258 & 2.92 & 54.2 & 72 & 265 & 68 & $2 \pi 2$ & 79 & 280 & 73 & 274 & 87 & 2.64 & 105 & 2.93 \\
\hline Nambia & 79 & 66 & 103 & 2.74 & 2.52 & 2.97 & 54.1 & 73 & 2.65 & 64 & 2.76 & 86 & 2.69 & 86 & 2.63 & 100 & 2.52 & 85 & 3.19 \\
\hline Ukraine & 80 & 70 & 95 & 2.74 & 2.60 & 287 & 53.8 & 116 & 230 & 84 & 2.49 & 95 & 2.59 & 95 & 2.55 & 61 & 2.96 & 54 & 3.51 \\
\hline Burkina Faso & 81 & 70 & 99 & 2.73 & 2.57 & 289 & 53.7 & 84 & 2.55 & 71 & 267 & 83 & 2.73 & 71 & 2.78 & 103 & 2.49 & 88 & 3.13 \\
\hline Lebaron & 82 & 54 & 136 & 272 & 231 & 3.12 & 53.2 & 66 & 273 & 74 & 264 & 75 & 2.84 & 108 & 2.45 & 78 & 2.75 & 111 & 2.86 \\
\hline E Salvador & 83 & 68 & 110 & 271 & 248 & 2.93 & 52.9 & 107 & 2.37 & 114 & 225 & 76 & 2.82 & 83 & 266 & 76 & 278 & 74 & 3.29 \\
\hline Morambique & 84 & 70 & 110 & 2.68 & 2.48 & 2.89 & 52.2 & 88 & 2.49 & 116 & 224 & 58 & 3.06 & 109 & 2.44 & 79 & 275 & 97 & 3.04 \\
\hline Guyana & 85 & 70 & 113 & 2.67 & 2.44 & 2.89 & 51.7 & 98 & 2.40 & 118 & 224 & 89 & 2.66 & 85 & 2.66 & 69 & 290 & 90 & 3.12 \\
\hline Moroccoo & 86 & 56 & 137 & 2.67 & 2.25 & 3.08 & 51.6 & 124 & 222 & 90 & 246 & 54 & 3.09 & 91 & 259 & 122 & 234 & 83 & 3.20 \\
\hline Bangladesh & 87 & 72 & 110 & 266 & 250 & 283 & 51.6 & 82 & 257 & 87 & 248 & 84 & 2.73 & 80 & 2.67 & 92 & 2.59 & 109 & 290 \\
\hline Ghana & 88 & 72 & 110 & 266 & 248 & 284 & 51.5 & 93 & 246 & 86 & 248 & 85 & 2.71 & 98 & 254 & 101 & 2.52 & 82 & 3.21 \\
\hline Costa Rica & 89 & 72 & 111 & 265 & 247 & 282 & 51.1 & 113 & 233 & 107 & 232 & 73 & 2.89 & 94 & 255 & 77 & 277 & 101 & 298 \\
\hline
\end{tabular}

Fuente: Banco Mundial, 2016

\section{El desempeño logístico regional y el desarrollo exportador}

La relación entre exportaciones y desempeño logístico es estrecha. Si observamos el ranking de exportadores e importadores mundiales de mercaderías y lo comparamos con el ranking global de desempeño logístico, vemos que existe una significativa correspondencia entre buen desempeño logístico y elevadas exportaciones, según muestra el Cuadro II. Así 
podemos observar que de los treinta primeros exportadores mundiales de mercaderías, diecinueve figuran también entre los treinta con mejor desempeño logístico. Tomando la mejor región comparada-OCDE-, Alemania que figura primero en el ranking de desempeño logístico, es el tercer exportador mundial; Estados Unidos que ocupa el puesto diez en desempeño logístico, es el segundo exportador mundial; Japón ubicado en el puesto doce del desempeño logístico, se ubica en el puesto cuarto como principal exportador mundial; Países Bajos se ubica en el puesto cuatro en desempeño logístico y en el quinto como exportador mundial o, el caso de Bélgica, que se ubica en el puesto sexto de desempeño logístico y en el decimotercero como exportador mundial. El buen funcionamiento de los componentes del desempeño logístico en un país es un facilitador del aumento de sus exportaciones. Esto es provocado por la mejora en los costos de los envíos -tanto para la provisión de insumos como para el suministro de bienes terminados-, por la previsibilidad en las entregas y la confiabilidad que esto conlleva, la optimización de tiempos y espacios y la seguridad sobre las mercaderías. Todas estas variables actuando positivamente, permiten diferenciar un producto de otros competidores del resto del mundo, sobre todo en países donde no existen o son escasas las otras variables de diferenciación. ${ }^{8}$

Aunque los servicios logísticos son brindados por y para organizaciones privadas, su desempeño depende en gran parte del sector público. Cuestiones como la infraestructura, los procedimientos aduaneros y las diferentes regulaciones al comercio exterior afectan la previsibilidad, los plazos de entrega, la puntualidad o la seguridad de un envío y son incumbencia del sector público. Por ello, podemos afirmar que sobre los Estados recae una porción fundamental de la responsabilidad en el desarrollo adecuado de cada componente logístico que será utilizado por cada organización para su internacionalización.

El informe que sobre logística y competitividad realizaran conjuntamente la CEPAL, OCDE y CAF, establece que América Latina y Caribe presentan un atraso considerable con respecto a la mejor región comparada -OCDE-, las reformas dadas en los últimos años son inferiores a otras zonas geográficas y existe divergencia significativa entre países de la región. ${ }^{9}$ Estos inconvenientes no fueron ajenos a su escaso protagonismo en el comercio internacional, fundamentalmente de manufacturas. Así, dentro de América Latina y como lo mostraba el cuadro I, Panamá posee el mejor desempeño regional, ubicándose recién en el puesto cuarenta con 3.34 puntos, seguido por Chile en el puesto cuarenta y seis con 3.25 puntos. Las divergencias entre países de la región se manifiestan cuando vemos en el mismo cuadro la diferencia entre el país mejor posicionado de América Latina -caso de Panamá-, con otros como Haití, quien presenta un retraso de casi el $50 \%$ en relación a aquel, o Bolivia, con retrasos del $33 \%$, Cuba con retrasos del $30 \%$ o Venezuela con el 29\%. Asimismo, países como Paraguay, Venezuela, Haití, El Salvador y Honduras empeoraron significativamente en la posición mundial con respecto a los índices de los años anteriores. ${ }^{10}$ Dentro de las causas del empeoramiento del desempeño, el índice LPI 2016 refiere a problemas como infraestructura y procesos aduaneros para el caso de Venezuela y Haití, problemas en tiempos de entrega para el

\footnotetext{
${ }^{8}$ El buen desempeño logístico es un importante facilitador de las exportaciones, si bien no es un determinante. Otras variables como la innovación o las tecnologías de última generación incorporadas al bien tienen gran peso al momento de exportar. Sin embargo, en aquellos países con altos costos de producción (ya sea por mano de obra, carga impositiva, costos de insumos, baja productividad u otros costos elevados), la eficiencia logística y la disminución de costos que ésta conlleva, contribuye a las exportaciones gracias a la diferenciación en los servicios agregados al bien. Esto es fundamental, ya que la competitividad de una empresa está afectada por los costos de transporte, portuarios o aduaneros. En países con costos de producción bajos, como es el caso de China (primer exportador mundial), un desempeño logístico que no alcanza su nivel óptimo (puesto número veintisiete en LPI) no impide el buen desempeño de las exportaciones debido a que éstas poseen una fuerte diferenciación en precios que neutralizan en cierto modo los costos mayores de la logística. Para otros detalles de impactos de costos logísticos sobre valor de bienes ver la nota al pie número 14 .

9 OCDE/CEPAL/CAF (2013), Perspectivas Económicas de América Latina 2014. Logística y competitividad para el desarrollo, París.

${ }^{10}$ Comparando con los Índices de Desempeño Logístico (LPI) -de los años 2012 y 2014-, presentados por el Banco Mundial en los informes correspondientes a esos años.
} 
caso de Paraguay, muy bajo nivel de infraestructura de transporte en los casos de Colombia, Guatemala y Perú y altos problemas de política aduanera en los casos de Argentina y Brasil. Si bien el informe muestra mejoras en algunas variables tales como desempeño de aduana en Colombia, trazabilidad y reducción de precios de envíos en Brasil o una mejora en una combinación de todas las variables en Uruguay, dichas mejoras en la región son inferiores a las demás zonas geográficas. Si tomamos el ranking de exportadores mundiales del cuadro II, observamos que -salvo México que se encuentra en el puesto número trece-, ningún otro país latinoamericano se encuentran entre los primeros veinte principales exportadores mundiales de mercaderías. Así, dentro de esta región, recién encontramos a Brasil en el puesto número veinticinco, seguido por Chile en el puesto número cuarenta y uno y Argentina en el puesto cuarenta y seis. El resto de países latinoamericanos ocupa posiciones más desventajosas después de los primeros cincuenta. La observación de esos dos rankings, nos muestra la relación entre buen desempeño logístico y desarrollo de las exportaciones. El magro desempeño logístico de un país genera, entre otros problemas, falta de previsibilidad y confiabilidad en los envíos, una variable muy importante de evaluación de importadores al momento de decidir una compra en otros mercados.

Uno de los grandes problemas que afectan a la logística regional se relaciona con el costo de los envíos. Entre ellos tenemos los altos costos de los fletes carreteros para trasladar la mercadería hasta el lugar de salida (ya sean puertos, aeropuertos, terminales interiores de carga, puntos de frontera) y los costos de los fletes internacionales para el traslado entre países de la región.

Sobre el primer obstáculo, en trayectos exclusivamente terrestres, el uso prevaleciente del camión en lugar de tren eleva considerablemente los costos del traslado hasta los puertos o aeropuertos de salida para los casos de exportaciones vía acuática o aérea. En los casos de exportaciones con uso exclusivo de transporte carretero -como es el caso de operaciones entre países vecinos-, el camión tiene un costo tan elevado que atenta contra la competitividad del producto transportado. Por ejemplo, tomando el caso de Argentina, un trayecto terrestre para el traslado de un contenedor desde el local del vendedor al puerto de salida utilizando solo camión, tiene un costo que duplica al mismo trayecto en cualquier país de la Unión Europea que utilice un sistema intermodal camión-tren. ${ }^{11}$ Esto genera que un producto que se pretende exportar desde Argentina elaborado lejos del puerto o aeropuerto de salida, tendría que soportar un costo de traslado interno más elevado que el producto elaborado en otros mercados, por lo cual el de la región se tornaría menos competitivo en su precio de venta una vez que se incluyeran en el mismo todos los costos necesarios para colocarlo en el lugar de salida. ${ }^{12}$

\footnotetext{
11 Según datos aportados por empresas especializadas en el traslado de contenedores y empresas transitarias -agentes de carga o freight forwarders- de Argentina. El transitario o Freight forwarder es un agente de cargas que se ocupa de la logística internacional, brindando servicios de traslado de mercaderías puerta a puerta entre diferentes países. Para ello, se nutre de una red de agentes en cada puerto, aeropuerto o ciudad desde donde sale o proviene el envío que debe coordinar.

12 Detalles comparativos de costos de traslados interiores podrán verse en el punto siguiente "El desempeño logístico de Argentina: un análisis de sus componentes”.
} 


\section{Cuadro II}

Principales exportadores e importadores 2015

\begin{tabular}{|c|c|c|c|c|c|c|c|c|c|}
\hline Rank & Exporters & Yalue | & Share & $\begin{array}{c}\text { Annual } \\
\text { percentage } \\
\text { change }\end{array}$ & Rank & Importers & Yalue & Share & $\begin{array}{c}\text { Annual } \\
\text { percentage } \\
\text { change }\end{array}$ \\
\hline 1 & China & 2275 & 13.8 & -3 & 1 & United States & 2308 & 13.8 & -4 \\
\hline 2 & United States & 1505 & 9.1 & -7 & 2 & China & 1682 & 10.1 & -14 \\
\hline 3 & Germany & 1329 & 8.1 & -11 & 3 & Germany & 1050 & 6.3 & -13 \\
\hline 4 & Japan & 625 & 3.8 & -9 & 4 & Japan & 648 & 3.9 & -20 \\
\hline 5 & Netherlands & 567 & 3.4 & -16 & 5 & United Kingdom & 626 & 3.7 & -9 \\
\hline 6 & Korea, Republic of & 527 & 3.2 & -8 & 6 & France & 573 & 3.4 & -15 \\
\hline \multirow[t]{3}{*}{7} & Hong Kong. China & 511 & 3.1 & -3 & 7 & Hong Kong, China & 559 & 3.3 & -7 \\
\hline & domestic exports & 13 & 0.1 & -16 & & retained imports & 134 & 0.8 & -11 \\
\hline & re-exports & 498 & 3.0 & -2 & & & & & \\
\hline 8 & France & 506 & 3.1 & -13 & 8 & Netherlands & 506 & 3.0 & -14 \\
\hline 9 & United Kingdom & 460 & 2.8 & -9 & 9 & Korea, Republic of & 436 & 2.6 & -17 \\
\hline 10 & Italy & 459 & 2.8 & -13 & 10 & Canada a & 436 & 2.6 & -9 \\
\hline 11 & Canada & 408 & 2.5 & -14 & 11 & Italy & 409 & 2.4 & -14 \\
\hline 12 & Belgium & 398 & 2.4 & -16 & 12 & Merico & 405 & 2.4 & -2 \\
\hline 13 & Mexico & 381 & 2.3 & -4 & 13 & India & 392 & 2.3 & -15 \\
\hline \multirow[t]{3}{*}{14} & Singapore & 351 & 2.1 & -14 & 14 & Belgium & 375 & 2.2 & -17 \\
\hline & domestic exports & 174 & 1.1 & -20 & & & & & \\
\hline & re-exports & 177 & 1.1 & -9 & & & & & \\
\hline 15 & Russian Federation & 340 & 2.1 & -32 & 15 & Spain & 309 & 1.8 & -14 \\
\hline \multirow[t]{2}{*}{16} & Switzerland & 290 & 1.8 & .7 & 16 & Singapore & 297 & 1.8 & -19 \\
\hline & & & & & & retained imports & 120 & 0.7 & -30 \\
\hline 17 & Chinese Taipei & 285 & 1.7 & -11 & 17 & Switzerland & 252 & 1.5 & -9 \\
\hline 18 & Spain & 282 & 1.7 & -13 & 18 & Chinese Taipei & 238 & 1.4 & -16 \\
\hline 19 & India & 267 & 1.6 & -17 & 19 & United Arab Emirates b & 230 & 1.4 & -8 \\
\hline 20 & United Arab Emirates b & 265 & 1.6 & -29 & 20 & Australia & 208 & 1.2 & -12 \\
\hline 21 & Thailand & 214 & 1.3 & -6 & 21 & Turkey & 207 & 1.2 & -14 \\
\hline 22 & Saudi Arabia, Kingdom of b & 202 & 1.2 & -41 & 22 & Thailand & 203 & 1.2 & -11 \\
\hline 23 & Malaysia & 200 & 1.2 & -15 & 23 & Russian Federation a & 194 & 1.2 & -37 \\
\hline 24 & Poland & 198 & 1.2 & -10 & 24 & Poland & 193 & 1.2 & -14 \\
\hline 25 & Brazil & 191 & 1.2 & -15 & 25 & Brazil & 179 & 1.1 & -25 \\
\hline 26 & Australia & 188 & 1.1 & -22 & 26 & Malaysia & 176 & 1.1 & -16 \\
\hline 27 & Viet Nam & 162 & 1.0 & 8 & 27 & Saudi Arabia, Kingdom of b & 172 & 1.0 & -1 \\
\hline 28 & Czech Republic & 158 & 1.0 & -10 & 28 & Viet Nam & 166 & 1.0 & 12 \\
\hline 29 & Austria & 152 & 0.9 & -15 & 29 & Austria & 155 & 0.9 & -15 \\
\hline 30 & Indonesia & 150 & 0.9 & -15 & 30 & Indonesia & 143 & 0.9 & -20 \\
\hline 31 & Turkey & 144 & 0.9 & -9 & 31 & Czech Republic & 140 & 0.8 & -9 \\
\hline 32 & Sweden & 140 & 0.8 & -15 & 32 & Sweden & 138 & 0.8 & -15 \\
\hline 33 & Ireland & 120 & 0.7 & 1 & 33 & South Africa b & 105 & 0.6 & -14 \\
\hline 34 & Norway & 105 & 0.6 & -27 & 34 & Hungary & 93 & 0.6 & -12 \\
\hline 35 & Hungary & 99 & 0.6 & -11 & 35 & Denmark & 86 & 0.5 & -14 \\
\hline 36 & Denmark & 95 & 0.6 & -14 & 36 & Norway & 76 & 0.5 & -15 \\
\hline 37 & South Africa & 82 & 0.5 & -10 & 37 & Slovak Republic & 74 & 0.4 & -10 \\
\hline 38 & Qatar & 77 & 0.5 & -39 & 38 & Ireland & 71 & 0.4 & -2 \\
\hline 39 & Slovak Republic & 76 & 0.5 & -13 & 39 & Philippines b & 70 & 0.4 & 3 \\
\hline 40 & Israel b & 64 & 0.4 & -7 & 40 & Romania & 70 & 0.4 & -10 \\
\hline 41 & Chile & 63 & 0.4 & -16 & 41 & Portugal & 67 & 0.4 & -15 \\
\hline 42 & Iran b & 63 & 0.4 & -29 & 42 & Egypt b & 65 & 0.4 & -9 \\
\hline 43 & Romania & 61 & 0.4 & -13 & 43 & Israel b & 65 & 0.4 & -14 \\
\hline 44 & Finland & 59 & 0.4 & -20 & 44 & Chile & 63 & 0.4 & -13 \\
\hline 45 & Philippines & 59 & 0.4 & -6 & 45 & Finland & 60 & 0.4 & -22 \\
\hline 46 & Argentina & 57 & 0.3 & -17 & 46 & Argentina & 60 & 0.4 & -8 \\
\hline 47 & Portugal & 55 & 0.3 & -14 & 47 & Colombia & 54 & 0.3 & -16 \\
\hline 48 & Kuwait, the State of & 55 & 0.3 & -47 & 48 & Iraq b & 52 & 0.3 & -12 \\
\hline 49 & Iraq b & 49 & 0.3 & -42 & 49 & Algeria & 52 & 0.3 & -12 \\
\hline \multirow[t]{3}{*}{50} & Nigeria b & 48 & 0.3 & -49 & 50 & Nigeria b & 48 & 0.3 & -20 \\
\hline & Total of above $c$ & 15420 & 93.6 & - & & Total of above $c$ & 15235 & 91.1 & - \\
\hline & Vorld $\mathrm{c}$ & 16482 & 100.0 & -13 & & Vorld $\mathrm{C}$ & 16725 & 100.0 & -12 \\
\hline
\end{tabular}

Fuente: OMC: World Trade Statistical Review 2016

Sobre el segundo obstáculo, y siendo el camión el medio preponderante para el comercio intrarregional latinoamericano, resulta más costoso trasladar un producto entre dos países vecinos de América Latina utilizando solo camión (por ejemplo entre Argentina y Brasil), que entre dos continentes utilizando el modo acuático (caso de traslados entre América y Asia). Así, mientras el costo del flete de un camión de 23 toneladas que recorre una distancia de 2.200 $\mathrm{km}$ entre ciudades de Argentina y Brasil, asciende aproximadamente a 3.000 dólares, el flete marítimo entre puertos de China y puertos de América del Sur como Santos (Brasil), 
Montevideo (Uruguay) o Buenos Aires (Argentina), asciende a 900 dólares. ${ }^{13}$ A esto hay que sumar que el modo acuático ha venido experimentando importantes disminuciones de tarifas desde la crisis del 2008 debido a la sobre oferta de espacio, con lo cual la brecha entre el costo del traslado terrestre y el acuático ha aumentado.

El tren es un medio de transporte que brinda importantes ventajas frente al camión. La principal de estas ventajas es su desempeño eficiente dada su capacidad de transportar en una misma formación grandes volúmenes de carga y así disminuir considerablemente la incidencia del costo de su funcionamiento sobre cada unidad transportada. Esta cualidad del ferrocarril genera, a su vez, otros beneficios, tales como un menor consumo de energía por unidad de tráfico, una menor emisión de gases de efecto invernadero, un menor nivel de accidentes y un bajo consumo de espacio público. El tren es el medio más apto para el transporte terrestre de grandes distancias, dado que sus costos variables son bajos en relación al camión. En función de sus ventajas y su impacto positivo en el comercio, el ferrocarril se convirtió en la opción de transporte terrestre más importante y relevante en el mundo moderno. Sin embargo, para ello se requiere una red ferroviaria con una distribución geográfica con suficientes interconexiones e infraestructura adecuada, vehículos que brinden prestaciones acordes a las nuevas exigencias internacionales y equipamiento acorde para el manipuleo de cargas en cada punto de origen y destino de la mercadería a trasladar.

Si bien a nivel global Argentina y Brasil se encuentran entre los países con más extensa red ferroviaria, en ambos casos la situación del sector dista considerablemente de aquella existente en los países que se encuentran en las posiciones más adelantadas en el ranking de exportadores y de desempeño logístico. Según señala Kohon, la productividad de vagones (en millones de toneladas-km por vagón en servicio) y de locomotoras (en millones de toneladas$\mathrm{km}$ por locomotora en servicio) es baja en relación a la cantidad de mercadería transportada, donde el camión es el principal actor. El transporte ferroviario de la región posee un nivel muy reducido al compararlo con la actividad ferroviaria mundial, dado que constituye alrededor del $3,5 \%$ del total de las unidades de tráfico (toneladas-km más pasajeros- $\mathrm{km}$ ) movilizadas por los aproximadamente cien países que poseen sistemas ferroviarios (Kohon, 2011).

La infraestructura y los servicios ferroviarios interurbanos en América Latina constituyen el sector que ha recibido menor atención por parte de los diferentes gobiernos de la región y esto ha generado que la participación del camión aumente de tal modo que en la actualidad es el medio preponderante. De esto se desprende que el precio de los envíos en América Latina se transforme en un obstáculo para un buen desempeño logístico y para la competitividad internacional.

\section{El desempeño logístico de Argentina: un análisis de sus componentes}

Enfocándonos en el desempeño logístico de Argentina, el índice la sitúa en el puesto número sesenta y seis en un total de ciento cincuenta países analizados. Este desempeño representa una caída con respecto al año 2014 de 6 puntos, pasando del lugar sesenta al sesenta y seis. Aún mayor es la caída si nos remitimos al año 2012, donde Argentina se ubicaba en el lugar cuarenta y cinco.

Lo anterior indica que Argentina posee un desempeño logístico que atenta contra la previsibilidad, la competitividad y por ende, contra la integración a las cadenas de valor mundiales. Considerando que la inserción internacional de un país a través de las exportaciones está íntimamente relacionada con su desempeño logístico -además de otros factores que hacen a la competitividad señalados anteriormente-, nos encontramos que en Argentina una de las

\footnotetext{
${ }^{13}$ Valores tomados en base a tarifas de transporte carretero cotizadas por empresas con permisos para brindar servicios de transporte entre Argentina y Brasil y empresas navieras que brindan servicios desde y hacia el Río de la Plata. Tarifas promedio vigentes entre abril y mayo de 2016 para camiones de 25 toneladas en el transporte carretero y contenedores de 40' dry box o de carga seca en transporte marítimo.
} 
causas del bajo nivel de exportaciones de manufacturas se relaciona a este magro desempeño y la falta de previsibilidad que ello conlleva. ${ }^{14}$

El problema exportador de manufacturas de Argentina viene de larga data. ${ }^{15}$ Más allá de nuestra fuerte presencia en los mercados internacionales de materias primas, las exportaciones de manufacturas nunca lograron un despegue que permitiera trasladar los beneficios a un desarrollo sustentable. ${ }^{16}$ Durante el año 2015, las exportaciones totales de Argentina disminuyeron un $0,56 \%$ con respecto al año anterior. Si bien esta disminución puede no ser demasiado significativa, el total de exportaciones de bienes y servicios tan solo representaron el $11 \%$ del PBI, un porcentaje bajo si comparamos con los principales exportadores mundiales que poseen mercados del tamaño de Argentina y si consideramos el promedio mundial, donde la participación media ha aumentado significativamente, pasando de un $20 \%$ en 1995 a un $30 \%$ en 2014 (en términos de valor). ${ }^{17}$ A su vez, el porcentaje argentino representa una suba poco

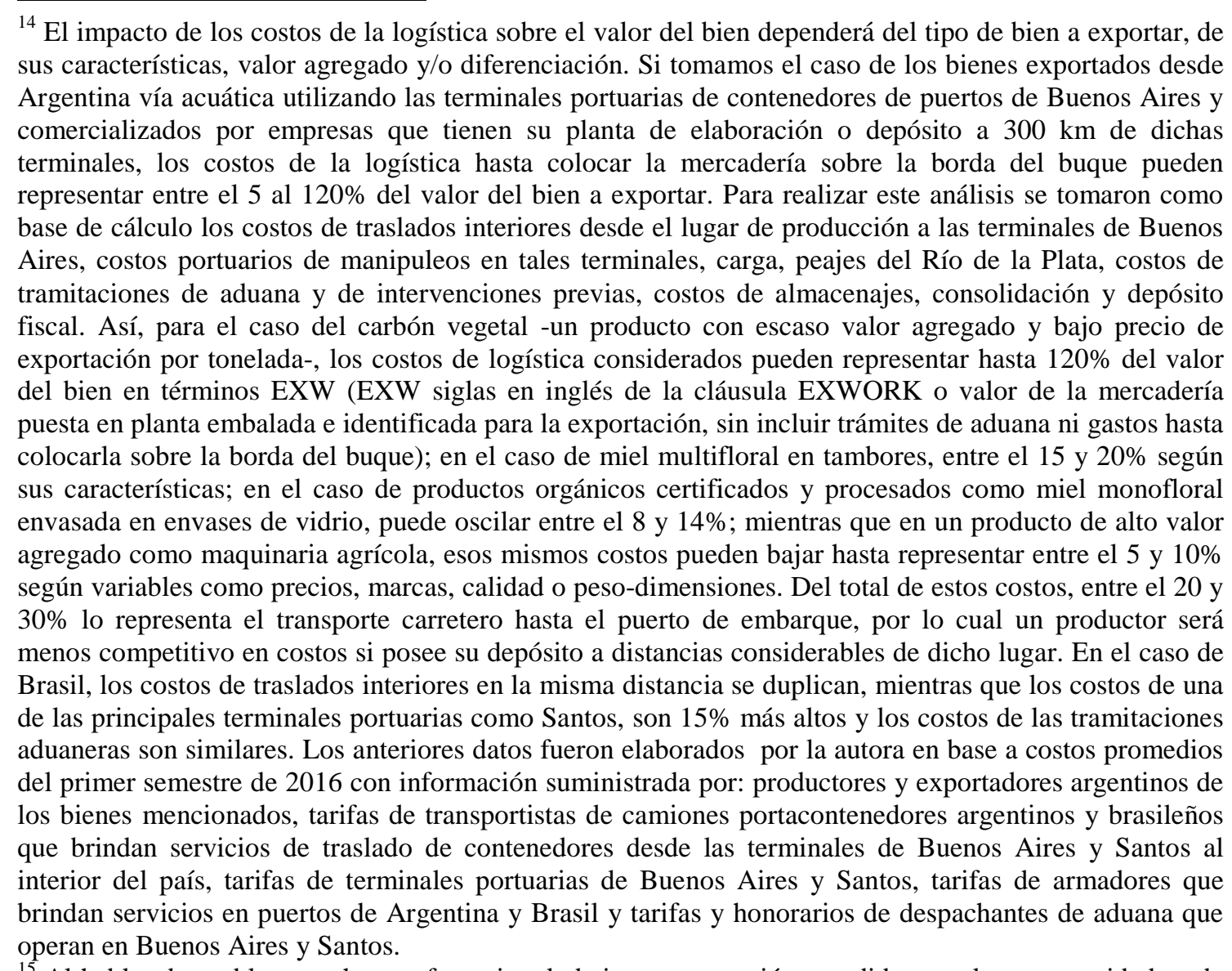

${ }^{15} \mathrm{Al}$ hablar de problema se hace referencia a la baja representación -medida en valores y cantidades- de exportaciones de productos manufacturados en las exportaciones totales de Argentina y a su concentración en productos agrícolas, así como al bajo porcentaje que las exportaciones totales de este país representan en el comercio mundial. Sobre lo primero, según estadísticas de la Organización Mundial de Comercio, las exportaciones argentinas del año 2015 estuvieron divididas en los siguientes grupos y porcentajes: productos agrícolas $60.9 \%$, combustibles y productos mineros $5.3 \%$, manufacturas $28.1 \%$, otros bienes 5.7\%. Sobre lo segundo, las exportaciones argentinas en 2015 representaron $0.3 \%$ de las exportaciones mundiales totales. Fuente: OMC Perfil comercial de Argentina. Disponible en http://stat.wto.org/CountryProfile/WSDBCountryPFView.aspx?Language=E\&Country=AR. Consulta: 4 de agosto de 2016.

${ }^{16}$ Un desarrollo sustentable de las exportaciones de manufacturas implica un aumento de la demanda de mano de obra y de su calificación, aumento del ingreso de divisas, mejoras salariales, incorporación de nuestras tecnologías, proyectos de inversión sostenidos en el tiempo y todos los beneficios indirectos que esto conlleva a la población.

${ }^{17}$ Según estadísticas elaboradas por la Organización Mundial del Comercio, Estadísticas del comercio mundial 2015 .

Disponible

en 
significativa si comparamos con la participación de las exportaciones en el PBI desde 1960 $(7.6 \%) .{ }^{18}$ El valor de las exportaciones en 2015 fue de 56.752 millones de dólares, lo cual nos ubica en el lugar cuarenta y seis del ranking de exportadores mundiales en función del valor exportado y en el puesto ciento cuarenta y tres de ciento ochenta y nueve en el listado de exportaciones con respecto al PBI. ${ }^{19}$

Entre los principales problemas que presentan los componentes del desempeño logístico de Argentina se replican los problemas regionales. Los altos costos del transporte hacia los lugares de salida o punto de frontera, los altos costos del manipuleo de las mercaderías en las terminales de carga y la burocracia en los procedimientos aduaneros, atentan contra la competitividad de los bienes exportables.

En cuanto al primero de los inconvenientes, lo vemos manifestado cuando observamos que el camión tiene la mayor participación del total de cargas transportadas en Argentina, en desmedro del tren. Lo anterior, es señalado por Martínez (2015:21) cuando afirma que "la participación del ferrocarril en el transporte nacional de cargas es incierta al no conocerse con precisión la carga movida por camión. Es posible que el ferrocarril lleve hoy en el orden del 3\% al 4\% de las toneladas-km totales; y como los trenes mueven las cargas de menor valor unitario, es claro que su participación en los fletes es menor aún. El rol del ferrocarril en la economía es mínimo, sin negar que conserve alguna importancia en el movimiento de unos pocos tráficos". Según sostienen Pérez Fiaño y Cano Tarruella (2016), la pérdida de protagonismo del tren en parte es explicada por la envergadura de las inversiones necesarias para su eficiente operación. La mayoría de los tramos ferroviarios que actualmente operan en América Latina fueron creados para favorecer las actividades extractivas del sector minero y agroexportador y solo en contadas excepciones, como un modo alternativo para el transporte de pasajeros o carga general. En la actualidad, no se ha cambiado demasiado ese patrón, dado que los ferrocarriles de cargas se dedican fundamentalmente a los tráficos masivos, en particular la minería -sobre todo mineral de hierro y carbón-, granos y subproductos y materiales de construcción. En muchísima menor medida, el ferrocarril se ocupa de tráficos de carga general con mayor valor agregado, en cuyo caso el camión ejerce una fuerte competencia. La carga general requiere un tipo de servicio de mayor calidad que las empresas ferroviarias de Argentina -orientadas a tráficos masivos-, no están brindando. Entre ellos podemos citar la necesidad de mayores frecuencias de servicios, puntualidad en las salidas y arribos, servicios eficientes de carga, descarga, manipuleos y almacenajes, costos conexos competitivos y terminales interiores de cargas que posibiliten el traspaso de contenedores y el transporte intermodal. En la actualidad, el transporte de carga general requiere de la intermodalidad y del empleo del contenedor, e implica, en muchos casos, la redefinición de la logística del sector público y privado. Esa prevalencia del camión por sobre el tren eleva los costos de la logística en Argentina, lo cual se traslada a un aumento de costos del bien a exportar. Por ejemplo, considerando una distancia de $300 \mathrm{~km}$ desde el lugar de producción al puerto de salida, para un contenedor de 20 ' de tipo estándar ${ }^{20}$ en un trayecto contratado ida y vuelta o round trip ${ }^{21}$, mientras el costo en Argentina utilizando solo

https://www.wto.org/spanish/res_s/statis_s/its2015_s/its15 highlights_s.pdf. Consulta: 18 de octubre de 2016.

18 Según datos del Banco Mundial disponibles en http://databank.bancomundial.org/data/reports.aspx? source=2\&series=NE.EXP.GNFS.ZS\&country=AR. Consulta: 18 de octubre de 2016.

${ }^{19}$ Según datos estadísticos de la Organización Mundial del Comercio, Estadísticas del comercio mundial 2015 , op. cit.

${ }^{20}$ Los contenedores de 20' tienen medidas interiores en cm que oscilan en: largo 588-589, ancho 233-235 y alto $238-239$ y pueden cargar hasta $28260 \mathrm{kgs}$.

${ }^{21}$ El itinerario round trip es el que contrata el exportador cuando retira a través de camión el contenedor vacío de la plazoleta del armador (muchas veces el puerto), lo traslada y posiciona en la planta o lugar de carga y consolidación, para finalmente conducirlo lleno al puerto para colocarlo al costado del buque a la espera de su carga. En función del ejemplo dado de una distancia de $300 \mathrm{~km}$, el trayecto round trip asciende a $600 \mathrm{~km}$. 
camión asciende a 850 dólares, en países de la Unión Europea con puertos sobre el Mediterráneo utilizando servicio intermodal camión-tren asciende a 460 dólares. ${ }^{22}$

Sobre el segundo aspecto, es decir los costos de las terminales de carga, descarga y manipuleos, Argentina duplica en las operaciones portuarias de contenedores a los costos existentes en los puertos de la Unión Europea. Si tomamos el caso de un contenedor de 20' estándar con 20 toneladas de peso, mientras que en Buenos Aires la suma de gastos de terminales portuarias y gastos de líneas marítimas -como peajes acuáticos y manipuleos-, ascienden aproximadamente a 500 dólares, en el caso de un puerto de la Unión Europea como Génova asciende a 260 dólares. $^{23}$ Además de estos altos costos, otro aspecto negativo lo constituyen la cantidad de conceptos -diferentes servicios- que conforman dichos costos. Los tarifarios de las terminales portuarias y movimientos de buques en muelle están compuestos por una multiplicidad de gastos que impide conocer detalladamente a qué corresponde cada uno, en qué casos hay que pagarlos y, en consecuencia, es difícil para un exportador Pyme no experimentado hacer una previsión del costo que tendrá un producto de exportación.

Esto implica que una manufactura producida en Argentina debería alcanzar un costo de producción más bajo que otros mercados que le permitiera compensar los mayores costos logísticos o, en su caso, tener un nivel de innovación y diferenciación que justifique ofrecerla al mundo a un precio más alto.

En cuanto a los procedimientos aduaneros, por un lado existen regulaciones que cambian con enorme frecuencia, generando incertidumbre empresaria y poca claridad al momento de planificar una exportación o importación. Por otro lado, existen requerimientos e inspecciones físicas a las mercaderías poco transparentes. Los controles muchas veces excesivos realizados en base a reglas poco claras derivan en la arbitrariedad de los inspectores, en la falta de transparencia de su accionar y en el cabildeo empresarial. Sin embargo, ese exceso de controles no ha impedido la ilegalidad del tráfico de exportación o importación y, a cambio, se observan demoras innecesarias en el tráfico legal que aumentan los costos de las cadenas de suministros, además de tornarlos impredecibles. Esto implica que muchos fabricantes de bienes exportables que utilizan insumos y componentes importados, se encuentren obligados a realizar cuantiosas compras externas y luego tener grandes y costosos stocks, solo a los fines de garantizar su provisión ante la incertidumbre en los procedimientos aduaneros futuros. Estas dificultades alejan a la empresa argentina de las innumerables ventajas del just in time en las cadenas de suministros aumentando sus costos.

\section{Conclusión}

De lo anterior se desprende que los indicadores del desempeño logístico de América Latina en general y de Argentina en particular afectan negativamente su inserción en el comercio internacional. Tal desempeño incide directamente sobre la competitividad de sus producciones y por tanto, el volumen de sus exportaciones. En regiones o países con altos costos en la cadena logística, es más necesario que los productos contengan alto valor agregado, innovación, diferenciación y diversificación, de modo que el costo logístico pase a representar un porcentaje menor en su precio final. Sin embargo, lo anterior es una cuestión que no fue resuelta aún en América Latina ni en Argentina. Como sostiene Lucángeli, "la falta de

\footnotetext{
${ }^{22}$ Datos suministrados por empresas transitarias -freight forwarders- de Argentina, Italia y España en base a tarifas que cotizan sus oficinas a exportadores en dichos países.

${ }^{23}$ Costos tomados en Argentina en base a promedios elaborados con costos de terminales portuarias de la ciudad de Buenos Aires para cargas de exportación, entre los que se incluyeron los siguientes conceptos: tasas a las cargas, manipuleo de recepción de contenedores dentro de los 5 días de zarpe del buque, entrega de contenedores de exportación, código PBIP, Control de Tráfico Vehicular Portuario (CTVP), THC y peaje del Río de la Plata. No se consideraron los costos de emisión de documentación, de coordinaciones logísticas, precintado y de almacenaje. Los tres primeros no se incluyeron porque varía según la línea marítima a utilizar y uno de ellos -la emisión de documentación- es percibido por ellas también en los demás puertos donde operan. El almacenaje no se incluyó porque las terminales otorgan 5 días libres. En Génova los costos incluidos fueron THC y código PBIP.
} 
diversificación de las exportaciones expone al sector externo a oscilaciones y eventualmente a presiones bajistas, una vez que se produce un cambio en la tendencia de los precios. Adicionalmente, una alta concentración de las exportaciones y una escasa complejidad de los productos exportados (con poco o nulo valor agregado) implican la existencia de una brecha respecto al potencial productivo de los países y refleja un pobre desempeño en términos de productividad y capacidad de innovación. Tal es el caso, por ejemplo, de varias economías de la región cuando se compara el grado de diversificación de sus ventas externas con el de otras economías de tamaño relativo" (Lucángeli, 2016).

Tanto Argentina como el resto de los países latinoamericanos necesitan orientar sus esfuerzos hacia una mayor diversificación, impulsando políticas de industrialización con fuerte enfoque en la innovación, el aumento de la complejidad de bienes y la formación de encadenamientos productivos que mejoren la productividad y la competitividad. Estas reformas deberán complementarse con una fuerte apuesta a la mejora de cada uno de los indicadores logísticos mencionados, lo que posibilitará encontrar nuevas oportunidades de negocios globales sustentables que alejaría a la región de los vaivenes económico-sociales que ha experimentado durante décadas.

Para que cada Estado y cada proveedor logístico con base en la región logren convertirse en verdaderos pilares de apoyo a las organizaciones en su tarea de expansión fronteras afuera, es importante focalizarse en cada componente del óptimo desempeño logístico como único modo de fortalecerlos. Por esto, se torna necesario atender estas cuestiones dándole un lugar prioritario en las agendas públicas y privadas arbitrando recursos y medios para ponerlo en acción.

\section{Referencias bibliográficas}

BANCO MUNDIAL (2012), Connecting to Compete 2012: Trade Logistics in the Global Economy. The Logistics Performance Index and Its Indicators, Washington DC.

BANCO MUNDIAL (2014), Connecting to Compete 2014: Trade Logistics in the Global Economy. The Logistics Performance Index and Its Indicators, Washington DC.

BANCO MUNDIAL (2015), Base de datos estadísticos 2015, Washington DC. Disponible en http://databank.bancomundial.org/data/reports.aspx ? source $=2 \&$ series=NE.EXP.GNFS.ZS \&country=AR Consulta: 18 de octubre de 2016.

BANCO MUNDIAL (2016), Connecting to Compete 2016: Trade Logistics in the Global Economy. The Logistics Performance Index and Its Indicators, Washington DC.

COUNCIL OF SUPPLY CHAIN MANAGEMENT PROFESSIONALS (2013), Supply Chain Management Terms and Glossary. Updated August 2013. Disponible en https://cscmp.org/sites/default/files/user_uploads/resources/downloads/glossary-

2013.pdf?utm source $=c s c m p s i t e \& u t m \_$medium $=$clicklinks\&utm content=glossary\&utm campaign $=$Glo ssaryPDF. Consulta: 2 de septiembre de 2016.

KOHON J. (2011), Más y mejores trenes. Cambiando la matriz de transporte en América Latina y el Caribe. Banco Interamericano de Desarrollo, Washington DC. Disponible en https://publications.iadb.org/bitstream/handle/11319/5241/M\%C3\%A1s\%20y\%20mejores\%20trenes\%20 Cambiando\%20la\%20matriz\%20de\%20transporte\%20en\%20Am\%C3\%A9rica\%20Latina\%20y\%20el\%2 OCaribe.pdf?sequence $=1$. Consulta: 2 de septiembre de 2016.

LUCÁNGELI, J. (2016), Las Exportaciones Extra-Regionales de Manufacturas de los Países Sudamericanos, Instituto para la Integración de América Latina y el Caribe (INTAL) Sector de Integración y Comercio (INT) NOTA TÉCNICA Nº IDB-TN-874, Banco Interamericano de Desarrollo, Washington DC, mayo.

MARTÍNEZ, J.P. (2015), ¿Tiene futuro en la Argentina la carga por ferrocarril?, en Revista Institucional, 1524, Año CIII, Bolsa de Comercio de Rosario, 13 de enero.

MESQUITA MOREIRA, M.; BLYDE, J.; VOLPE MARTINCUS, C. y MOLINA, D. (2013), Muy lejos para exportar: Los costos internos de transporte y las disparidades en las exportaciones regionales en América Latina y el Caribe, Banco Interamericano de Desarrollo, Washington DC. 
MUIR, J. (2016), Cerrar la brecha de infraestructura: ¿puede el desarrollo de la infraestructura potenciar la competitividad comercial?, Blog Mas allá de las fronteras, Banco Interamericano de Desarrollo, Washington, DC. Disponible en http://blogs.iadb.org/integracion-comercio/2016/04/13/cerrarla-brecha-de-infraestructura-puede-el-desarrollo-de-la-infraestructura-potenciar-la-competitividadcomercial/. Consulta: 30 de abril de 2016.

OCDE/CEPAL/CAF (2013), Perspectivas Económicas de América Latina 2014. Logística y competitividad para el desarrollo, París.

ORGANIZACIÓN MUNDIAL DE COMERCIO (2015). Estadísticas del comercio mundial 2015. Disponible en https://www.wto.org/spanish/res_s/statis_s/its2015_s/its15 highlights_s.pdf. Consulta: 5 de julio de 2016.

PÉREZ FIAÑO, J. y CANO TARRUELLA, I. (2016), Lecciones aprendidas para el desarrollo de Megaproyectos de Transporte en América Latina y el Caribe, en Revista ALAF, (100), Buenos Aires. 